\title{
1 Development and optimization of a high-throughput 3D rat Purkinje neuron culture
}

2 Running head: Rat Purkinje neuron culture

3

4 Ida M. Uggerud (MSc) ${ }^{1,2}$, Torbjorn Krakenes (MSc) ${ }^{2}$, Hirokazu Hirai ${ }^{3}$ (MD, PhD), Christian

$5 \quad$ A. Vedeler $(\mathrm{MD}, \mathrm{PhD})^{1,2,4}$, Manja Schubert $(\mathrm{ScD})^{* 1}$

$6{ }^{1}$ Department of Neurology, Haukeland University Hospital, 5021 Bergen, Norway

$7 \quad{ }^{2}$ Department of Clinical Medicine (K1), University of Bergen, 5021 Bergen, Norway

$8{ }^{3}$ Department of Neurophysiology \& Neural Repair, Gunma University Graduate School of

9 Medicine, Maebashi, Gunma 371-8511, Japan

$10{ }^{4}$ Neuro-SysMed - Centre of Excellence for Experimental Therapy in Neurology, Departments

11 of Neurology and Clinical Medicine, 5021 Bergen, Norway

13 Address correspondence to:

14 Dr. Manja Schubert, ScD

15 Department of Neurology

16 Haukeland University Hospital

17 N-5021 Bergen, Norway

18 Tel: (47) 55586715

19 Fax: (47) 55586410

20 Email: schubert_manja@hotmail.com

21

22 Title:

23 Running head:

24 Abstract:

25 Article:

26 Material and Methods:

27 Statements:

28 Figure legends:

TOTAL:

Number of figures/tables:

80 characters

27 characters

564 characters

9644 characters

10507 characters

754 characters

4177 characters

Main text:

25646 characters

3

1461 words 
bioRxiv preprint doi: https://doi.org/10.1101/2020.05.20.105858; this version posted May 22, 2020. The copyright holder for this preprint (which

was not certified by peer review) is the author/funder, who has granted bioRxiv a license to display the preprint in perpetuity. It is made available under aCC-BY-NC-ND 4.0 International license.

1 Keywords: Purkinje neuron; neuronal culture system; neurodegeneration

2

3 Abbreviations: DIV = days in vitro PN = Purkinje neuron; $\mathrm{PNC}=$ Purkinje neuron culture;

$4 \mathrm{SCL}=$ support cell layer

5 


\section{Abstract}

2 Improved understanding of the mechanisms involved in neurodegenerative disease has been

3 hampered by the lack of robust cellular models that faithfully replicate in vivo features. Here,

4 we present a refined protocol for generating age-dependent, well-developed and synaptically

5 active rat Purkinje neurons, responsive to paracrine factors and supporting a 3D cell network.

6 Our model provides high experimental flexibility, high-throughput screening capabilities and

7 reliability to elucidate Purkinje neuron function, communication and neurodegenerative

8 mechanisms.

9

\section{Article}

11 Unravelling the mechanisms of neurodegeneration depends on the availability of robust

12 models that provide insight both at the single cell level and network levels, and that offer high

13 experimental flexibility. Dissociated neuronal cultures can be useful, but their quality and

14 survival dependents on several factors including animal species, age of tissue that is dispersed

15 to give single cells, the surface onto which the single cells are seeded and cultured, and co-

16 factors that drive neuronal growth and development. To date, the majority of successful

17 Purkinje neuron cultures (PNC) models have used embryonic mouse cerebellum, few have

18 successfully used rat embryonic or postnatal cerebellum. Although the success rate of

19 transgenic alterations and in vivo modelling is lower in rats ${ }^{1}$, the rat is physiologically,

20 genetically and morphologically closer to humans than the mouse ${ }^{2}$, and outbred or transgenic

21 rat models mimic human neurodegenerative disease mechanisms and progressions more

22 closely ${ }^{3-5}$ than mouse models do ${ }^{6,7}$.

23 Since neurodegeneration generally occurs in the adult or aged human brain, a

24 dissociated culture system derived from mature rather than embryonic tissue is desirable.

25 However, previous attempts to culture functional dissociated neurons from late postnatal and

26 adult tissue have been largely unsuccessful. Therefore, our goal was to develop a culture 
1 protocol that provided well-developed, mature, functional and synaptically active rat Purkinje

2 neurons (PNs), interdependent of the derived tissue age, that gaves maximal experimental

3 flexibility and the potential for high-throughput screening. We discovered three factors that

4 were essential for success: having a three-dimensional (3D) growth structure, $\mathrm{pH}$ stability and

5 co-factor supplementation.

The first attempt growing PNs directly on glass cover-slips coated with poly-D-lysine

7 (PDL) and the extracellular matrix protein laminin failed: the yield of PNs per cover-slip

8 declined to zero from E18 to P10 at 21 days in vitro (DIV) (Figure 1a, non 3D-SCL). We

9 reasoned that the extracellular matrix used lacked important features including other cell types

that provide the in vivo 3D cell network structure and thereby cell-cell communicate including

11 paracrine factor secretion. Therefore, in the second attempt we developed a three-

12 dimensional support cell layer (3D-SCL) approach by plating two cerebellar cell layers

13 derived of either E18, P0 or P10 tissue onto PDL coated cover-slips. We introduced a time-

14 delay by plating the second cell layer 7 to 48 days later than the first. We found that the tissue

15 age of cells used to grow the 3D-SCL (E18 to P10) had no impact on the PN yield of the

second layer, however, there was a strong correlation between the in vivo age of the support cell layer and the tissue age used to grow the second cell layer, the enriched PN layer. The highest survival rate of E18 derived-PNs was observed when plated onto the 3D-SCL at DIV14, for P0 derived-PNs at DIV21 and for P10 derived-PNs at DIV28 (Figure 1a). These

20 findings indicate that the older the starting tissue, the more mature the 3D-SCL has to be to 21 achieve a high survival rate of PNs for a minimum of 21 to $28 \mathrm{DIV}$.

However, the use of a "double" cell layer was associated with higher metabolic demand than single layer cultures and led to non-physiological $\mathrm{pH}$ fluctuations resulted in cell death when half of the culture media was replaced ones a week. Replacing the culture media more frequently, either every 3.5-days (6 well) or every 2-days (12 and 24 well) prevented 26 pathological $\mathrm{pH}$ fluctuations and gave a healthy well-developed neuronal network. Despite 
1 this, immunofluorescent staining showed that the PNs had a poorly developed dendritic

2 morphology compared to those in vivo, with fewer and shorter branches in E18 and P0

3 derived-PNs (Figure 1b-c, 1 b upper panel).

$4 \quad$ Neuronal dendrites are generated during development by a series of processes

5 involving a first step of extension and retraction of dendritic branches, and subsequently

6 stabilisation of existing dendrites through building of synaptic connections and neuronal

7 calcium homeostasis ${ }^{8}$. Calcium-dependent protein kinase $\mathrm{C}$ (PKC) subtypes, activated by

8 synaptic inputs from the parallel fibres (granule cells) through metabotropic glutamate

9 receptors (mGluR1/4), trigger functional changes as well as long-term anatomical maturation

10 of the PN dendritic tree during cerebellar development ${ }^{9}$. Altering the activity of calcium-

11 dependent PKC subtypes using PKC antagonist K252a improved dendritic branching for E18

12 and P0 derived-PNs similar to in vivo, but had no effect on the branching characteristics of

13 P10 derived-PNs (Figure 1b-c, 1b lower panel). Interestingly, K252a-induced PKC inhibition

14 significantly improved the low survival rate observed for P0 and particularly for P10 derived-

15 PNs in a concentration dependent manner (Figure 1d). The survival rate in P0 derived-PNs

16 was improved by a factor of 6 by blocking $20 \%$ of PKC activity (10 nM K252a), whereas in

17 P10 derived-PNs, blocking PKC activity to $50 \%$ (25 nM K252a) increased the survival rate

18 by a factor of 28. Inhibiting PKC activity had no effect on the survival rate of E18 derived-

19 PNs (Figure 1d).

20 PN survival and dendritic tree development are also highly dependent on paracrine

21 factors such as progesterone, insulin and insulin-like growth factor 1 (IGF1) secreted by other

22 cells or self-produced by PNs in an age-dependent manner ${ }^{10-12}$. We supplemented our culture

23 with $40 \mu \mathrm{M}$ progesterone and found this led to increased branched dendritic trees in E18

24 derived-PNs, but it had no impact on the branch structure of P0 and P10 derived-PNs (Figure

25 1e). Even though PN dendritic development was insufficient when either K252a inhibition or

26 progesterone were not supplied, supplementation with insulin and IGF1 were sufficient to 
1 maintain the long-term growth of the other cerebellar cell types: granule, Golgi, Lugaro,

2 unipolar brush, stellate and basket cells (Figure 1f).

3 To demonstrate that our PNs expressed functional synapses, we used

4 immunocytochemistry to identify pre- and postsynaptic biomarkers of functional synapses

5 including voltage-gated calcium channels (VGCC), metabotropic glutamate receptor 1

6 (mGluR1), post-synaptic density protein 95 (PSD95), glutamate-decarboxylase 65 (GAD65),

7 glycine transporter 2 (GlyT2), $\alpha$-synuclein and bassoon. All these markers were present

8 indicating a level of maturity of both the PNs and the surrounding network (Figure 1g).

9 Next, we tested the functional activity of these PNs. In vivo, PNs fire spontaneous

10 action potentials at frequencies of about $40-50 \mathrm{~Hz}$ with a complex trimodal pattern of tonic

11 firing, bursting, and silent modes that depend on anatomically and functionally maturity ${ }^{13,14}$.

12 E18 derived-PNs cultured in a 24 well multielectrode array first revealed spontaneous

13 bioelectrical activity on in vitro day 11 . The spike rate increased constantly from $0.15 \pm 0.03$

$14 \mathrm{~Hz}(D I V 11)$ to $2.56 \pm 0.59 \mathrm{~Hz}(D I V 21)$. After DIV28, the spike activity become erratic with

15 long periods of silence, but overall, a frequency of $2.79 \pm 0.55 \mathrm{~Hz}$ was maintained until

16 DIV63 (Figure 1h). We observed uniform, highly non-uniform spike intervals and trains with

17 silent periods between bursts and spike frequencies of up-to $140 \mathrm{~Hz}$ within the burst.

18 Exchanging the PNC media at DIV28 to one previously used in organotypic brain slice culture

$19{ }^{15}$, prevented the erratic spike activity and stabilized the spike frequency at $6.35 \pm 1.85 \mathrm{~Hz}$ for 20 up-to 63 DIV.

21 In addition to immunocytochemical and high-throughput electrophysiological studies,

22 this 3D PN model system will provides the potential for cell-type-specific genetic

23 engineering. For example, by using lentiviral particles to express $\mathrm{PN}$-specific green

24 fluorescence protein (GFP) via implementation of the $\mathrm{L} 7$ promoter ${ }^{16,17}$. To test this, we

25 applied L7-GFP inducing viral particles to dissociated PNs on the day of seeding. Within 3

26 days, we found PNs expressing GFP and hardly any off-targets $(<0.02 \%)$. At DIV14, $61.5 \%$ 
1 of the PN population were GFP positiveand these cells did not differ in dendritic structure and

2 stably expressed GFP for up-to 169 DIV (Figure 1i). Using our culture system, we also found

3 a sufficiently high transfection rate of PNs when lentiviral particles were added to the culture

4 at DIV14 and DIV28, however the rate of transfection and speed of expression fell

5 progressively the later the genetic manipulation was implemented. The GFP positive PNs in

6 the culture revealed a very similar development to in vivo, as we were able to observed the

7 fusion phase (E17-P5), the phase of stellate cells with disoriented dendrites (P5-P7), as well

8 as the phase of orientation and flattering of the dendritic tree (P7-P21) ${ }^{18,19}$ (Figure 1i).

9 We present a 3D, rat PNC model for growing Purkinje neurons that is independent of 10 derived tissue age, and which provides a complex and robust system that allows maximal 11 experimental flexibility. The combined use of 3D network structures (3D-SCL) with 12 optimized concentrations and time-dependent addition of hormones, paracrine factors and 13 activity regulators (progesterone, insulin, IGF-1, K252a), created ideal conditions to grow a 14 balanced cerebellar network in miniature (Figure 2). As a proof-of-principle, we 15 demonstrated the usefulness of this culture model as a high-throughput screening tool to investigate disease mechanisms including drug/compound testing. The long-term stability and 17 neuronal complexity of our culture will facilitate the study of cell- and network-dependent cerebellar degeneration related to paraneoplastic cerebellar degeneration and ataxia.

\section{Material and Methods}

\section{Neuronal culture preparation.}

23 All procedures were performed according to the National Institutes of Health Guidelines for 24 the Care and Use of Laboratory Animals Norway (FOTS 20135149/20157494/20170001). 25 Wistar Hannover GLAST rat pups $(\mathrm{n}=328)$, embryonic day 18 (E18) to postnatal day 10 26 (P10), were used for neuronal culture preparation. 
1 Briefly, following anaesthesia and decapitation, the brains were rapidly transferred into

2 preparation solution: ice-cold EBSS solution (Gibco, \#24010043) containing 0.5\% glucose

3 (Sigma, \#G8769) and $10 \mathrm{mM}$ HEPES (Gibco, \#15630056). Under a dissection microscope,

4 carefully remove the meninges, cut off the medulla oblongata and separate the cerebellum

5 from the pons and the midbrain. Depending on the culture, Purkinje neuron or structural layer,

6 transfer either only the cerebellum or the cerebellum including pones to a $15 \mathrm{~mL}$ tube

7 containing $20 \mathrm{U} / \mathrm{mL}$ papain (Worthington, \#LK003178) solved in preparation solution and

8 warmed up to $36^{\circ} \mathrm{C}$. Place the tube into the incubator for 15 minutes at $36^{\circ} \mathrm{C}$ with

9 occasionally swirling to digest the tissue. Remove the papain solution carefully with a fire

10 polished Pasteur pipette and stop the digestion by adding pre-warmed stop media $\left(36^{\circ} \mathrm{C}\right)$ :

11 advanced DMEM/F12 solution (Gibco, \#12634010) containing 0.5\% glucose (Sigma,

12 \#G8769) and 10\% foetal bovine serum (FBS, Gibco, \#10500064). After 5 minutes of

13 deactivation, remove the stop media and add $250 \mu \mathrm{L}$ growth media containing $10 \%$ FBS per

14 cerebellum and pipette the tissue/media suspension with a fire polished Pasteur pipette 100X

15 until cells are separated.

17 3D Support Cell Layer (3D-SCL).

18375000 cells $/ \mathrm{mL}$ from cerebellum including pones were seeded on pre-coated coverslides 19 from Neuvitro (\#GG-12-1.5-PDL, 24 well, $500 \mu \mathrm{L} /$ well; \#GG-18-1.5-PDL, 12 well, 1 20 mL/well; \#GG-25-1.5-laminin, 6 well, 2 mL/well). Culture were maintained in 6-,12- or 2421 well plates in growth media consisting of $45 \%$ advanced DMEM/F12 solution (Gibco, \# 22 126340010), 45\% NBM solution (Miltenyibiotec, \#130-093-570), 1.5\% B-27 serum-free 23 supplement (Gibco, \#17504044), 1.5\% NB-21 serum-free supplement (Miltenyibiotec, \#13024 093-566), 1\% NaPyruvate (Invitrogen, \#11360088), 1\% heat-inactivated FBS (Invitrogen, 25 \#10500064), 2\% GluTAMaX (Gibco, \#35050038), $5 \mathrm{mg} / \mathrm{mL}$ D-glucose and $10 \mathrm{mM}$ HEPES 26 (Invitrogen, \#15630056) at $36^{\circ} \mathrm{C}$. Half of the culture medium was replaced every 7 days. 


\section{Purkinje neuron layer.}

3 E18 and P0 derived Purkinje neuron culture: 500000 cells $/ \mathrm{mL}$ from cerebellum without pones

4 were seeded on the 3D support cell layer of different in vitro ages. P10 derived Purkinje

5 neuron culture: 750000 cells $/ \mathrm{mL}$ from the vermis of the cerebellum were seeded on the 3D

6 support layer of different in vitro ages. The growth media was supplemented with insulin

7 (Invitrogen, \#12585014; 1:250, stock 4 mg/mL), progesterone (Sigma, \#P8783, 1:2000, stock

$880 \mathrm{mM}$ ), insulin-like growth factor 1 (IGF1; Promokine, \#E-60840, 1:40000, stock $1 \mu \mathrm{g} / \mu \mathrm{L}$ )

9 and Protein kinase C inhibitor K252a (Alomone, \# K-150; $\mathrm{IC}_{50} 25 \mathrm{nM}$ ). In long-term cultures

10 that were maintained for more than 28 days in vitro the IGF1 and progesterone concentration

11 were reduced to $10 \mathrm{ng} / \mathrm{mL}$ and $20 \mu \mathrm{M}$, respectively. K252a was supplemented for 21 days

12 before the washout process started, its optimal concentration was experimental evaluated for

13 each tested culture type. Half of the culture medium was replaced every 3.5 (6 well) and 2

14 (12/24 well) days, respectively. All experiments testing the Purkinje neuron yield dependent

15 on derived tissue age, in vitro age of the 3D-SCL and K252a concentration were performed

16 randomly, containing 3 to 6 probes per experimental setting and 5 independently repeats for

17 each group and condition.

\section{Lentiviral gene editing.}

20 L7 promoter (full length 1005 bp) were custom cloned by SBI System Bioscience into 21 construct pCDH-L7-MCS-copGFP (\#CS970S-1) and viral particle with a yield of $2.24 \times 10^{9}$ 22 ifus $/ \mathrm{mL}$ were produced. Freshly prepared Purkinje neurons of E18 or P0 cerebellum 23 suspended in growth media containing no serum were incubated for 10 minutes at $37{ }^{\circ} \mathrm{C}$ with $241.22 \times 10^{6}$ viral particle/mL before seeded onto the supplement structure layer containing 25 cover-slip or live cell imaging $\mu$-dish (\#80136, $35 \mathrm{~mm}$, Ibidi). Media was changed after 3 26 days and transfection efficiency evaluated by live cell imaging microscopy $24 \mathrm{~h}$ post 
1 transfection, daily up to 21 days and weekly up to 169 days in culture, respectively.

2 Additional, lentiviral transfection of Purkinje neurons in culture were performed 1 day after

3 feeding at DIV15 and DIV29 by applying $2.5 \times 10^{6}$ viral particle/mL to evaluate the

4 efficiency and effects of age-dependent genetic manipulations. The neuronal development of

5 the GFP expressing Purkinje neurons was followed by obtaining 10 independent $3 \times 3$ tile scan

6 using the Zyla camera configuration (2048x2048) with the CFI Plan Apochromat Lambda dry

7 objective 10x0.45 (pixel size $603 \mathrm{~nm}$ ) or 20x0.75 (pixel size $301 \mathrm{~nm}$ ) at the Andor Dragonfly

8 microscope system (Oxford Instruments company). The experiments of DIV0, DIV15 and

$9 \quad$ DIV29 were repeated three times.

\section{Immunohistochemical cell type characterisation.}

12 To evaluate Purkinje neuron yield and the distribution ratio of other cell types of the 13 cerebellum, including their synaptic interactions, the culture was washed with pre-warmed 0.1 14 M PBS (1xPBS; Gibco, \#70013016) and fixed with 1.5-4\% paraformaldehyde (PFA, pH 615 7.2; ThermoScientific, \#28908) containing $0.5 \%$ sucrose for 15 minutes at $36^{\circ} \mathrm{C}$. Tris-based 16 or citric acid-based heat induced antigen retrieval ( $\mathrm{pH} 9$ and $\mathrm{pH} 6 ; 45 \mathrm{~min}, 85^{\circ} \mathrm{C}$ ) ${ }^{20}$ were 17 perform when necessary (see Table 1). Culture were quenched with 1xPBS containing $50 \mathrm{mM}$ $\mathrm{NH}_{4} \mathrm{Cl}\left(\mathrm{PBS}_{\mathrm{N}}\right)$, permeabilised with $0.2 \%$ Triton X-100 (Sigma, \#T9284) in $\mathrm{PBS}_{\mathrm{N}}(5$ min, $\left.1936^{\circ} \mathrm{C}\right)$, rinsed with $\mathrm{PBS}_{\mathrm{N}}$ containing $0.5 \%$ cold water fish gelatine (Sigma, $\left.\# \mathrm{G} 7041\right)\left(\mathrm{PBS}_{\mathrm{NG}}\right.$, $203 \times 15 \mathrm{~min}$ ), and incubated with primary antibody over-night at $4^{\circ} \mathrm{C}$ in $\mathrm{PBS}_{\mathrm{NG}}$ containing $10 \%$ 21 Sea Block (SB; ThermoScientific, \#37527), 0.05\% Triton X-100 and $100 \mu \mathrm{M}$ glycine 22 (Sigma, \#G7126) to visualise the different cerebellar cell types, including Purkinje neurons 23 and their synaptic interactions (Table 1). The cover-slips were rinsed with $\mathrm{PBS}_{\mathrm{NG}}(3 \times 20 \mathrm{~min})$ 24 and incubated with highly cross-absorbed donkey secondary antibodies conjugated to $25 \mathrm{CF}^{\mathrm{TM}}$ 488/594/647-Dye (1:400; Biotium, \#20014, \#20115, \#20046, \#20015, \#20152, \#20047, $26 \# 20074$, \#20075, \#20169, \#20170) for 2 hours at $22^{\circ} \mathrm{C}$ in $\mathrm{PBS}_{\mathrm{NG}}$ containing $2.5 \% \mathrm{SB}$. To 
1 remove unbound secondary antibody cover-slips were rinsed with $\mathrm{PBS}_{\mathrm{N}}(3 \times 20 \mathrm{~min})$, and

2 briefly tipped into MilliQ water before mounted in hardening Prolong ${ }^{\mathrm{TM}}$ Glass Antifade

3 Reagent (Invitrogen, \#P36981) onto cover-slides. After 2 days of hardening at $18-21^{\circ} \mathrm{C}$ in the

4 dark, cover-slides were stored at $4{ }^{\circ} \mathrm{C}$ until imaging.

\section{Purkinje neuron count and imaging.}

7 Purkinje neurons were counted manually and blind by screening the cover-slips using a Leitz

8 Diaplan Fluorescence microscope equipped with CoolLED pE-300white. For dendritic tree

9 branch analysis and determination of maturity and synaptic interaction, 10 Purkinje neuron

10 Z-stack images per cover-slide were collected in 5 independent and randomized experiments

11 at $0.5-1 \mu \mathrm{m}$ intervals with the Zyla camera configuration (2048x2048) at the Andor Dragonfly

12 microscope system using either a CFI Plan Apochromat Lambda S LWD 40x1.14 water

13 objective (pixel size $151 \mathrm{~nm}$ ), 60x1.20 oil objective (pixel size $103 \mathrm{~nm}$ ) or CFI SR HP Apo TIRF

14 100x1.49 oil objective (pixel size $60 \mathrm{~nm}$ ) to detect DAPI and $\mathrm{CF}^{\mathrm{TM}} 488 / 594 / 647$ dye emission

15 and superimposed with Fusion software (Oxford Instruments). 3D surface visualization of

16 synapses was performed using Oxford Instruments analysis software IMARIS 9.3.1 and the

17 filament tracer tool ${ }^{21}$.

\section{Dendritic tree branch analysis.}

The Purkinje neuron dendritic tree development was evaluated by analysing group

21 dependent 10 Purkinje neurons per experiment in 10 independent experiments towards the 22 order and length of the dendritic arbours by using an open-source ImageJ and Fiji plugin

23 Simple_Neurit_Tracer (Neuroanatomy) ${ }^{22}$.

\section{Micro-electrode array (MEA) recordings.}


1 Primary cultures of E18 derived-PNs at a concentration of 500000 cells $/ \mathrm{mL}$ were 2 plated onto PDL precoated 24 well format plate of the Multiwell-MEA-system (Multi

3 Channel System-MCS, Reutlingen, Germany). Each well contains 12 PEDOT coated gold

4 micro-electrodes (30 $\mu \mathrm{m}$ diameter, $300 \mu \mathrm{m}$ space, 3 x 4 geometrical layout) on glass base to

5 facilitate visual checking (\#890850, 24W300/30G-288). The amplifier (data resolution: 24 bit;

6 bandwidth: $0.1 \mathrm{~Hz}$ to $10 \mathrm{kHz}$, modifiable via software; default $1 \mathrm{~Hz}$ to $3.5 \mathrm{kHz}$; sampling

7 frequency per channel: $50 \mathrm{kHz}$ or lower, software controlled; input voltage range: \pm 2500

$8 \mathrm{mV}$ ), stimulator (current stimulation: $\max . \pm 1 \mathrm{~mA}$; voltage stimulation: $\max . \pm 10 \mathrm{~V}$;

9 stimulation pattern: pulse or burst stimulation sites freely selectable) and heating element

10 (regulation: $\pm 0.1^{\circ} \mathrm{C}$ ) is integrated in the Multiwell-MEA-headstage which is driven by the

11 MCS-Interface Board 3.0 Multiboot. The Multiwell recording platform is covered by a mini

12 incubator to provide $5 \% \mathrm{CO}_{2}$ and balanced air. Electrophysiological signals were acquired at a

13 sampling rate of $20 \mathrm{kHz}$ through the commercial software Multiwell-Screen. Plates were

14 tested every second day for spontaneous activity from day 5 in vitro. Raw voltage traces were

15 recorded for 120 seconds, saved and analysed using offline MCS-Multiwell-Analyzer to

16 calculate spike rate and burst activity, including network properties. Two experimental

17 settings were tested: number 1 recording of spontaneous spike activity in Purkinje neuron

18 culture media (45\% advanced DMEM/F12 solution, 45\% NBM solution, $1.5 \%$ B-27 serum-

19 free supplement, $1.5 \%$ NB-21 serum-free supplement, $1 \%$ NaPyruvate, $1 \%$ heat-inactivated

20 FBS, 2\% Glutamax, $5 \mathrm{mg} / \mathrm{mL}$ D-glucose, $10 \mathrm{mM}$ HEPES, $16 \mu \mathrm{g} / \mathrm{mL}$ insulin, $25 \mathrm{ng} / \mathrm{mL}$

21 IGF1, $40 \mu \mathrm{M}$ progesterone, $5 \mathrm{nM} \mathrm{K252a)}$ for 63 days and number 2 recording spontaneous

22 spike activity for the first 28 days in Purkinje neuron culture media but then exchanged to

23 organotypic brain slice culture media ${ }^{15}$ (30\% advanced DMEM/F12 solution, 20\% MEM

24 solution (\#41090028; Gibco), 25\% EBSS solution (\#24010043; Gibco), 25\% heat-inactivated

25 horse serum (\#H1138; Sigma), 2\% GLUTAMAX, 5 mg/ml D-glucose and 2\% B-27 serum-

26 free supplement) for the remaining 45 days. 
2 Notes to provide stable high yield Purkinje neuron culture.

3 (1) All media should be prepared fresh on the day of use.

(2) Prevent repeated thaw-freeze cycles of the supplements

(3) 3D-SCL should be fed 24 hours prior plating of the second cell layer, PN layer, to provide stable $\mathrm{pH}$ at 6.8 to 7.0 on the day of seeding.

\section{ACKNOWLEDGMENT}

9 The authors thank Y.Ishizuka and C.E.Bramham for providing the E18 cerebellum tissue, C.

10 Elliott for discussion, and the Molecular Imaging Centre (MIC), where the imaging

11 experiments were performed (Department of Biomedicine and the Faculty of Medicine and

12 Dentistry of University of Bergen). This work was funded by grants from HelseVest Norway 13 and University of Bergen.

\section{AUTHOR CONTRIBUTIONS}

M.S. devised the conceptual framework. I.M.U., T.K and M.S planned and performed the 17 experiments and analysed the obtained data sets. H.H. provided the lentiviral approach. The paper was written by M.S, H.H. and C.A.V. with editing contributions from all the authors.

\section{COMPETING FINANCIAL INTERESTS}

21 The authors declare no competing financial interests. 


\section{REFERENCES}

2

3 1. Bugos, O., Bhide, M. \& Zilka, N. Beyond the rat models of human neurodegenerative

4 disorders. Cell. Mol. Neurobiol. 29, 859-869 (2009).

5 2. Jacob, H. J. \& Kwitek, A. E. Rat genetics: attaching physiology and pharmacology to the

6 genome. Nat. Rev. Genet. 3, 33-42 (2002).

7 3. Drummond, E. \& Wisniewski, T. Alzheimer's disease: experimental models and reality.

$8 \quad$ Acta Neuropathol. (Berl.) 133, 155-175 (2017).

9 4. Nuber, S. et al. A progressive dopaminergic phenotype associated with neurotoxic

10 conversion of $\alpha$-synuclein in BAC-transgenic rats. Brain J. Neurol. 136, 412-432 (2013).

11 5. von Hörsten, S. et al. Transgenic rat model of Huntington's disease. Hum. Mol. Genet. 12,

$12 \quad 617-624(2003)$.

6. Ellenbroek, B. \& Youn, J. Rodent models in neuroscience research: is it a rat race? Dis.

$$
\text { Model. Mech. 9, 1079-1087 (2016). }
$$

7. Dawson, T. M., Golde, T. E. \& Lagier-Tourenne, C. Animal models of neurodegenerative diseases. Nat. Neurosci. 21, 1370-1379 (2018).

8. Metzger, F. Molecular and cellular control of dendrite maturation during brain development. Curr. Mol. Pharmacol. 3, 1-11 (2010).

9. Metzger, F. \& Kapfhammer, J. P. Protein kinase C: its role in activity-dependent Purkinje cell dendritic development and plasticity. Cerebellum Lond. Engl. 2, 206-214 (2003).

10. Wessel, L. et al. Long-term incubation with mifepristone (MLTI) increases the spine density in developing Purkinje cells: new insights into progesterone receptor mechanisms. Cell. Mol. Life Sci. CMLS 71, 1723-1740 (2014).

11. Croci, L. et al. Local insulin-like growth factor I expression is essential for Purkinje neuron survival at birth. Cell Death Differ. 18, 48-59 (2011). 
1 12. Hami, J. et al. Stereological study of the effects of maternal diabetes on cerebellar

2 cortex development in rat. Metab. Brain Dis. 31, 643-652 (2016).

3 13. Armstrong, D. M. \& Rawson, J. A. Activity patterns of cerebellar cortical neurones

4 and climbing fibre afferents in the awake cat. J. Physiol. 289, 425-448 (1979).

5 14. Womack, M. \& Khodakhah, K. Active Contribution of Dendrites to the Tonic and

6 Trimodal Patterns of Activity in Cerebellar Purkinje Neurons. J. Neurosci. 22, 10603-

$7 \quad 10612(2002)$.

8 15. Schubert, M., Panja, D., Haugen, M., Bramham, C. R. \& Vedeler, C. A. Paraneoplastic

9 CDR2 and CDR2L antibodies affect Purkinje cell calcium homeostasis. Acta Neuropathol.

10 (Berl.) 128, 835-852 (2014).

11 16. Hirai, H. Basic research on cerebellar gene therapy using lentiviral vectors.

12 Cerebellum Lond. Engl. 11, 443-445 (2012).

13 17. Nitta, K., Matsuzaki, Y., Konno, A. \& Hirai, H. Minimal Purkinje Cell-Specific

14 PCP2/L7 Promoter Virally Available for Rodents and Non-human Primates. Mol. Ther.

15 Methods Clin. Dev. 6, 159-170 (2017).

16 18. McKay, B. E. \& Turner, R. W. Physiological and morphological development of the

17 rat cerebellar Purkinje cell: Purkinje cell output parallels dendritic development. J. Physiol.

$18 \quad 567,829-850(2005)$.

19 19. Kapfhammer, J. P. Cellular and molecular control of dendritic growth and

20 development of cerebellar Purkinje cells. Prog. Histochem. Cytochem. 39, 131-182 (2004).

21 20. Emoto, K., Yamashita, S. \& Okada, Y. Mechanisms of heat-induced antigen retrieval:

22 does $\mathrm{pH}$ or ionic strength of the solution play a role for refolding antigens? J. Histochem.

23 Cytochem. Off. J. Histochem. Soc. 53, 1311-1321 (2005).

24 21. De Bartolo, P., Florenzano, F., Burello, L., Gelfo, F. \& Petrosini, L. Activity-

25 dependent structural plasticity of Purkinje cell spines in cerebellar vermis and hemisphere.

26 Brain Struct. Funct. 220, 2895-2904 (2015). 
bioRxiv preprint doi: https://doi.org/10.1101/2020.05.20.105858; this version posted May 22, 2020. The copyright holder for this preprint (which

was not certified by peer review) is the author/funder, who has granted bioRxiv a license to display the preprint in perpetuity. It is made available under aCC-BY-NC-ND 4.0 International license.

1 22. Longair, M. H., Baker, D. A. \& Armstrong, J. D. Simple Neurite Tracer: open source

2 software for reconstruction, visualization and analysis of neuronal processes. Bioinforma.

3 Oxf. Engl. 27, 2453-2454 (2011).

4

5

6 


\section{FIGURE LEGEND}

2 Figure 1 | Evaluation of age-dependent rat Purkinje neuron culture. (a) Interdependent

3 relationship of Purkinje neuron yield and in vitro age of the 3D support cell lager (3D-SCL:

4 DIV 7 to 48) for E18, P0 and P10 derived-Purkinje neurons. (b) Representative Purkinje

5 neuron skeletons dependent on derived neuron age, 3D-SCL and protein kinase C (PKC)

6 antagonist K252a. Scale bar, $20 \mu \mathrm{m}$; (c) Analysis of dendritic branch structure towards length

7 and branch orders for Purkinje neurons derived from E18, P0 and P10 tissue without and with

$825 \mu \mathrm{M} \mathrm{K252a}$ to modulate PKC activity. (d) Interdependent relationship of Purkinje neuron

9 yield and concentration-dependent PKC activity modulation for E18, P0 and P10 derived-

10 Purkinje neurons. (e) Representative skeleton of an E18 derived-Purkinje neurons visualizing

11 the effect of $40 \mu \mathrm{M}$ progesterone on dendritic branching. Scale bar, $20 \mu \mathrm{m} ;$ (f)

12 Immunohistochemical representation of the major cell types (white) forming the 3D-SCL:

13 unipolar brush cells (CAL- calretinin), granule cells (GABAAR $\alpha 6$ ), Golgi cells (NG-

14 neurogranin, GlyT2), Lugaro cells (GlyT2), stellate and basket cells (PAV-parvalbumin),

15 fibres such as mossy and climbing (VGluT2, PP-peripherin), oligodendrocytes (CNP1) as

16 well as microglia (IBA1). Nuclei staining DAPI (blue). Scale bar, $50 \mu \mathrm{m}$; (g)

17 Immunohistochemical representation of mature Purkinje neurons (green; CB-calbindin, PCP2

18 - Purkinje cell specific protein 2) positive for post- and presynaptic biomarkers (magenta).

19 Postsynaptic: VGCC, mGluR1, and PSD95 including 3D IMARIS cartoon reconstruction of

20 the protein positive synapses on one chosen Purkinje neuron dendrite; Pre-synaptic: $\alpha$ -

21 synuclein ( $\alpha$-syn) - marker of glutamatergic synaptic terminals from granule cells (parallel

22 fibres) and unipolar brush cells (type I/II); GAD65- marker of axon terminals from stellate

23 and basket cells; bassoon - marker of the active zone of mossy fibre terminals and parallel

24 fibre terminals between Golgi cells and granule cells, and between basket cells and Purkinje

25 neurons; and synapsin I - synaptic vesicle phosphoprotein of mature CNS synapses; Nuclei

26 staining DAPI (blue). Scale bar, $20 \mu \mathrm{m}$; (h) MEA recorded spike patterns (10s) with a cut-out 
1 (1s) at day 21 in vitro following Purkinje neuron maturity. (i) Live-cell imaging of E18

2 derived-Purkinje neuron expressing lentiviral-induced GFP from day of seeding (DIV0) up to

32 months (DIV53). The Purkinje neuron development to maturity was very similar to in vivo,

4 as the fusion phase (E17 - P5 $\approx$ DIVO - DIV7), the phase of stellate cells with disoriented

5 dendrites (P5 - P7 $\approx D I V 7-D I V 9)$, as well as the phase of orientation and flattering of the

6 dendritic tree $(\mathrm{P} 7-\mathrm{P} 21 \approx D I V 9-D I V 23)$ were observed. Scale bar, $50 \mu \mathrm{m}$

8 Figure 2 | Optimized 3D rat Purkinje neuron culture protocol. Each tested culture desired 9 different conditions of support and activity interdependent of the starting tissue age. Whereas the supplementation of insulin-like growth factor 1 (IGF1) and progesterone (PROG) induced a stable environment to obtain high survival rates of Purkinje neurons, PKC activity modulation mainly shaped the dendritic tree development, with the exception of P10 tissue derived neurons where the survival was highly dependent on the inhibition of PKC but not their dendritic tree development. The optimized protocol for all tested tissues relies on the time point of placing the second cell layer, the Purkinje neuron enriched layer, and media that is supplemented with IGF1, progesterone and K252a, where K252a starting concentration is

17 altered dependent on the used tissue to start the culture as follow; DIV1-10: E18 - $5 \mathrm{nM}, \mathrm{P0}$ $10 \mathrm{nM}, \mathrm{P} 10$ - $25 \mathrm{nM}$; DIV10-22: the K252a concentration is raised to $25 \mathrm{nM}$ for E18 and P0 until the dendritic tree is well-developed and mature; DIV22-28: washout phase, K252a supplementation is stopped (DIV22-24: $12.5 \mathrm{nM}$, DIV24-26: $6.75 \mathrm{nM}$, DIV26-28: $3.35 \mathrm{nM}$ ).

21 At DIV 28 the IGF1 and progesterone concentration is reduced by factor, 2.5 and 2, respectively, to proceed to long-term culture conditions. The developed protocol allows to 23 grow a stable Purkinje neuron 3D culture for up to 6 months (DIV163) in a 6 to 24 well 24 format. 
Table 1 | Primary antibodies. The signal to noise ratio for the antibodies were evaluated for the following conditions: $4 \%$ PFA at pH 7.2 diluted in 100 mM PBS; $1.5 \%$ PFA at pH 6 diluted in 100mM natrium acetate buffer ( $\mathrm{NaAcB}$ )); without heat-induced antigen retrieval (HIAGR); and with HIAGR either TRIS-based ( $\mathrm{pH}$ 9) or citric acid-based ( $\mathrm{pH} 6)$. The best conditions for each used antibody are described below.

\begin{tabular}{|c|c|c|c|c|c|c|c|c|c|}
\hline Antibody & Species & Company & Cat. No. & LOT No. & RRID & $\begin{array}{l}\text { Dilution } \\
{[\mu \mathrm{g} / \mathrm{mL}]}\end{array}$ & PFA fixation & HIAGR & Marker \\
\hline A-Synuclein & chicken & EnCorBio & CPCA-SNCA & 71113 & AB_2572385 & 1.0 & 1.5\%; pH 6; NaAcB & No & $\begin{array}{l}\text { Pre-synapse, granule and } \\
\text { unipolar brush cells /PNs }\end{array}$ \\
\hline Bassoon & chicken & SYSY & 141016 & $141016 / 1-1$ & AB_2661779 & $\begin{array}{l}\text { Serum } \\
1: 500\end{array}$ & $4 \%, \mathrm{pH} 7.2 ; \mathrm{PBS}$ & No & $\begin{array}{l}\text { Pre-synapse; Golgi / } \\
\text { granule cells, or basket } \\
\text { cells / PNs }\end{array}$ \\
\hline \multirow[t]{2}{*}{ Calbindin } & $\begin{array}{l}\text { guinea } \\
\text { pig }\end{array}$ & SYSY & 214005 & $214005 / 1-5$ & AB_2619902 & 0.5 & $4 \%, \mathrm{pH} 7.2 ; \mathrm{PBS}$ & No & Purkinje neurons \\
\hline & chicken & SYSY & 214006 & $214006 / 1-3$ & AB_2619903 & $\begin{array}{l}\text { Serum } \\
1: 750\end{array}$ & $4 \%, \mathrm{pH} 7.2 ; \mathrm{PBS}$ & No & Purkinje neurons \\
\hline Calretinin & chicken & SYSY & 214106 & $214106 / 2$ & AB_2619909 & $\begin{array}{l}\text { Serum } \\
1: 500\end{array}$ & $4 \%, \mathrm{pH} 7.2 ; \mathrm{PBS}$ & No & Unipolar-brush cells \\
\hline CNP1 & rabbit & SYSY & 355003 & $355003 / 1-2$ & AB_2620112 & 1.0 & $4 \%, \mathrm{pH} 7.2 ; \mathrm{PBS}$ & No & Oligodendrocytes \\
\hline $\mathrm{GABA}_{\mathrm{A}} \mathrm{R} a 6$ & rabbit & SYSY & 224603 & $224603 / 3$ & AB_2619945 & 5.0 & 4\%, pH 7.2; PBS & $\mathrm{pH} 9$ & Granule cells \\
\hline GAD65 & mouse & $\begin{array}{l}\text { BD Bio- } \\
\text { science }\end{array}$ & 559931 & 4283665 & AB_397380 & 2.5 & 1.5\%; pH 6; NaAcB & No & $\begin{array}{l}\text { Pre-synapse, stellate and } \\
\text { basket cells / PNs }\end{array}$ \\
\hline GlyT2 & $\begin{array}{l}\text { guinea } \\
\text { pig }\end{array}$ & SYSY & 272004 & $27004 / 2$ & AB_2619998 & $\begin{array}{l}\text { Serum } \\
1: 250\end{array}$ & $4 \%, \mathrm{pH} 7.2 ; \mathrm{PBS}$ & $\mathrm{pH} 6$ & Golgi cells; Lugaro cells \\
\hline IBA1 & rabbit & EnCorBio & RPCA-IBA1 & 266_100517 & AB_2722747 & 1.0 & $4 \%, \mathrm{pH} 7.2 ; \mathrm{PBS}$ & No & microglia \\
\hline mGluR1 & $\begin{array}{l}\text { guinea } \\
\text { pig }\end{array}$ & FRONTIER & 2571801 & & AB_2571801 & 2.5 & $1.5 \% ; \mathrm{pH} 6 ; \mathrm{NaAcB}$ & No & PNs, Lugaro cells \\
\hline Neurogranin & rabbit & SYSY & 357003 & $357003 / 1$ & AB_2620115 & 2.5 & $4 \%, \mathrm{pH} 7.2 ; \mathrm{PBS}$ & No & Golgi cells \\
\hline Parvalbumin & $\begin{array}{l}\text { guinea } \\
\text { pig }\end{array}$ & SYSY & 195004 & $195004 / 1-21$ & AB_2156476 & $\begin{array}{l}\text { Serum } \\
1: 500\end{array}$ & $4 \%, \mathrm{pH} 7.2 ; \mathrm{PBS}$ & No & $\begin{array}{l}\text { PNs, basket and stellate } \\
\text { cells }\end{array}$ \\
\hline PCP2 & rabbit & Takara & M194 & $1 \mathrm{AFXJ002.0}$ & & 1.0 & $4 \%, \mathrm{pH} 7.2 ; \mathrm{PBS}$ & No & Purkinje neurons \\
\hline Peripherin & rabbit & EnCor Bio & RPCA-Peri & 0208_070316 & AB_2572375 & 0.5 & $4 \%, \mathrm{pH} 7.2 ; \mathrm{PBS}$ & No & Mossy and climbing fibers \\
\hline PSD95 & mouse & $\begin{array}{l}\text { Neuro } \\
\text { mab }\end{array}$ & $75-028$ & 455.7JD.22G & AB_2292909 & 5.0 & 1.5\%; pH 6; NaAcB & No & Post-synapse \\
\hline Synapsin 1/2 & chicken & SYSY & 106006 & $106006 / 1-4$ & AB_2622240 & $\begin{array}{l}\text { Serum } \\
1: 500\end{array}$ & 1.5\%; pH 6; NaAcB & No & Pre-synapse \\
\hline $\begin{array}{l}\text { VGCC-PQ } \alpha- \\
1 A\end{array}$ & $\begin{array}{l}\text { guinea } \\
\text { pig }\end{array}$ & SYSY & 152205 & $152205 / 3$ & AB_2619842 & 4.0 & 1.5\%; pH 6; NaAcB & No & Purkinje neuron synapse \\
\hline VGluT2 & $\begin{array}{l}\text { guinea } \\
\text { pig }\end{array}$ & SYSY & 135404 & $135404 / 2-32$ & AB_887884 & $\begin{array}{l}\text { Serum } \\
1: 500\end{array}$ & $4 \%, \mathrm{pH} 7.2 ; \mathrm{PBS}$ & $\mathrm{pH} 6$ & $\begin{array}{l}\text { Mossy and climbing } \\
\text { fibers }\end{array}$ \\
\hline
\end{tabular}




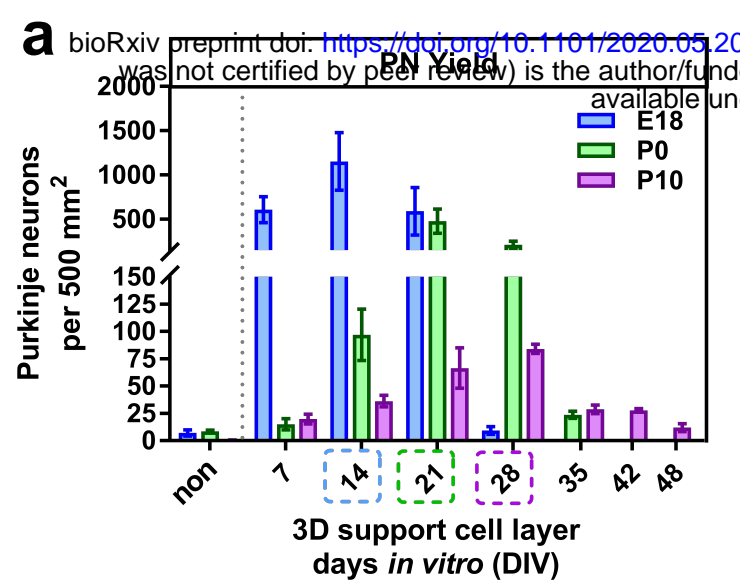

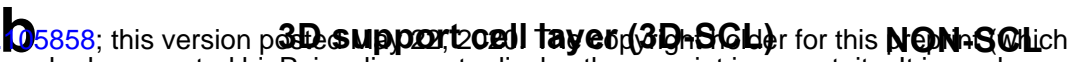
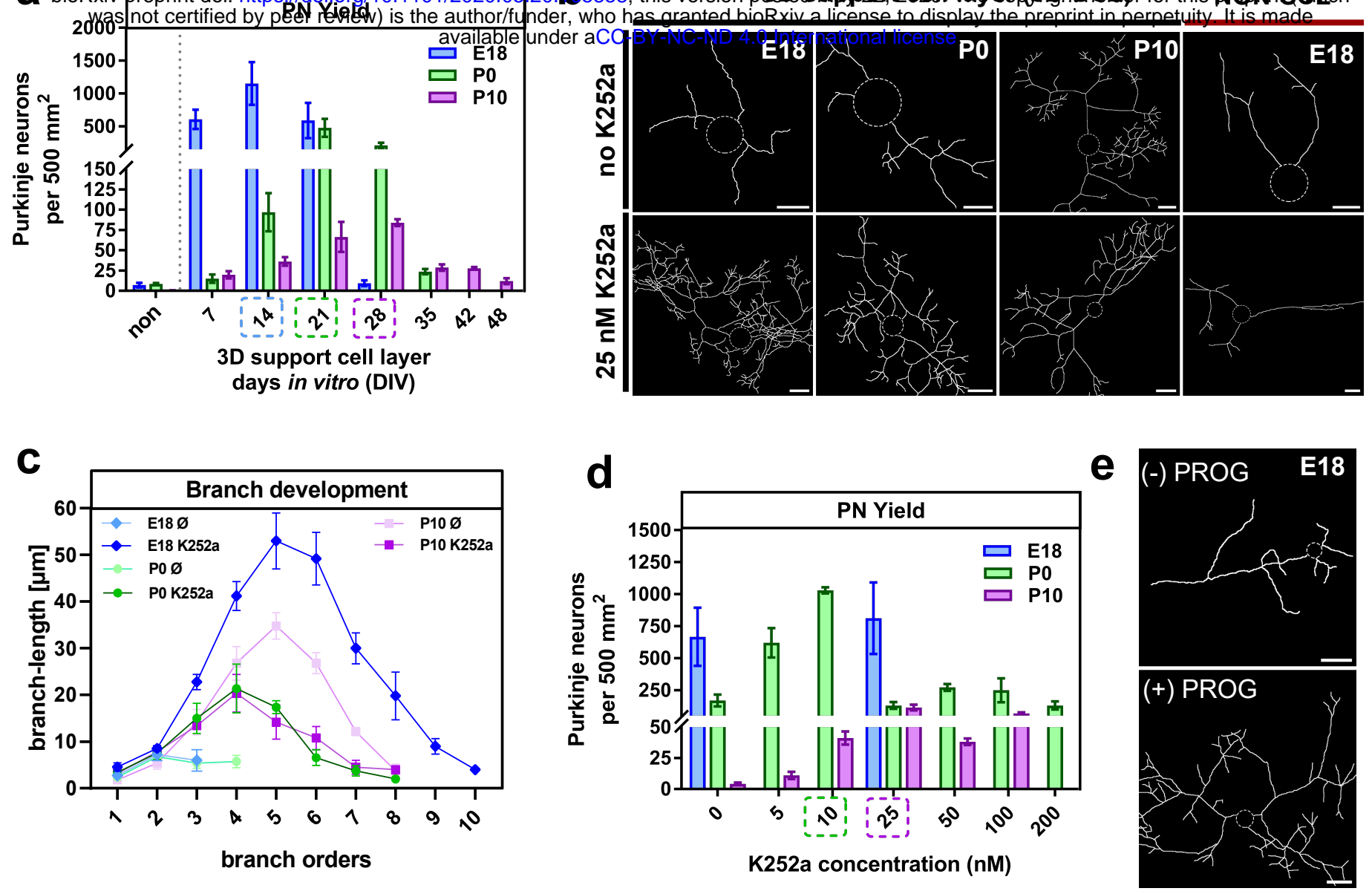

g
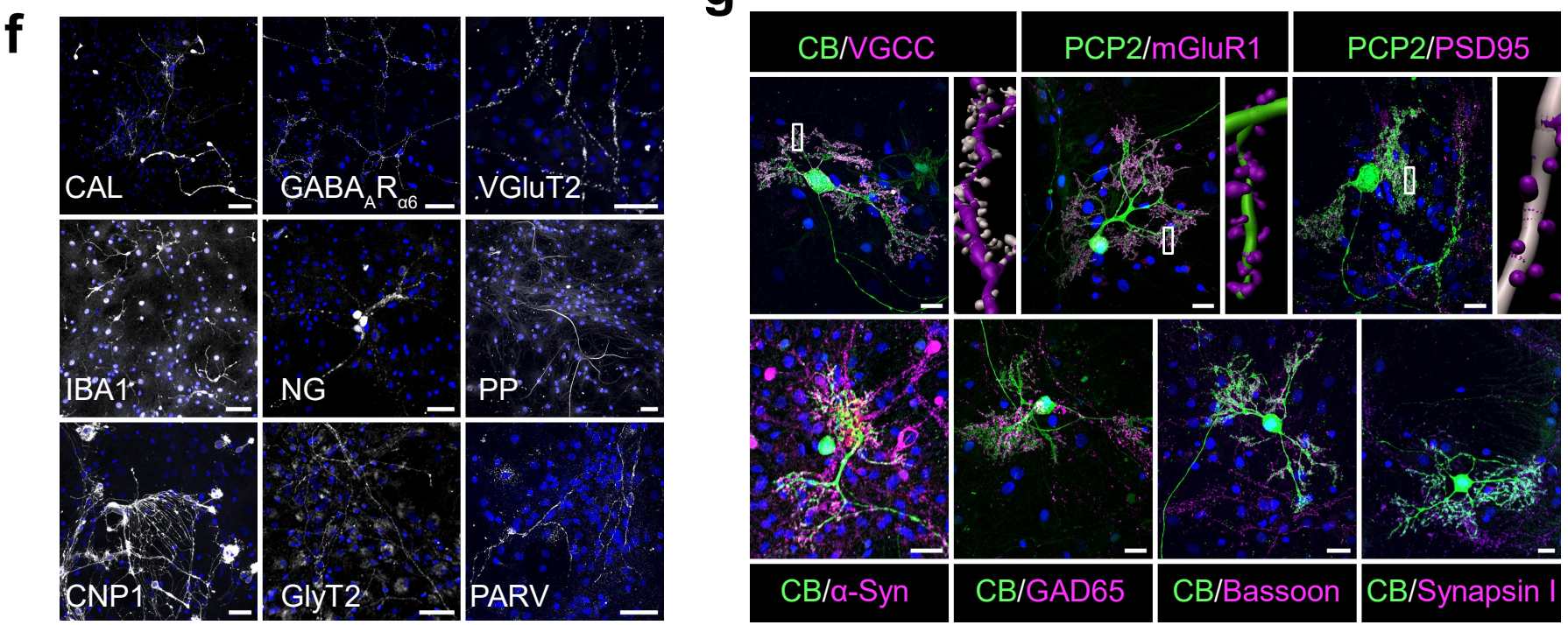

h
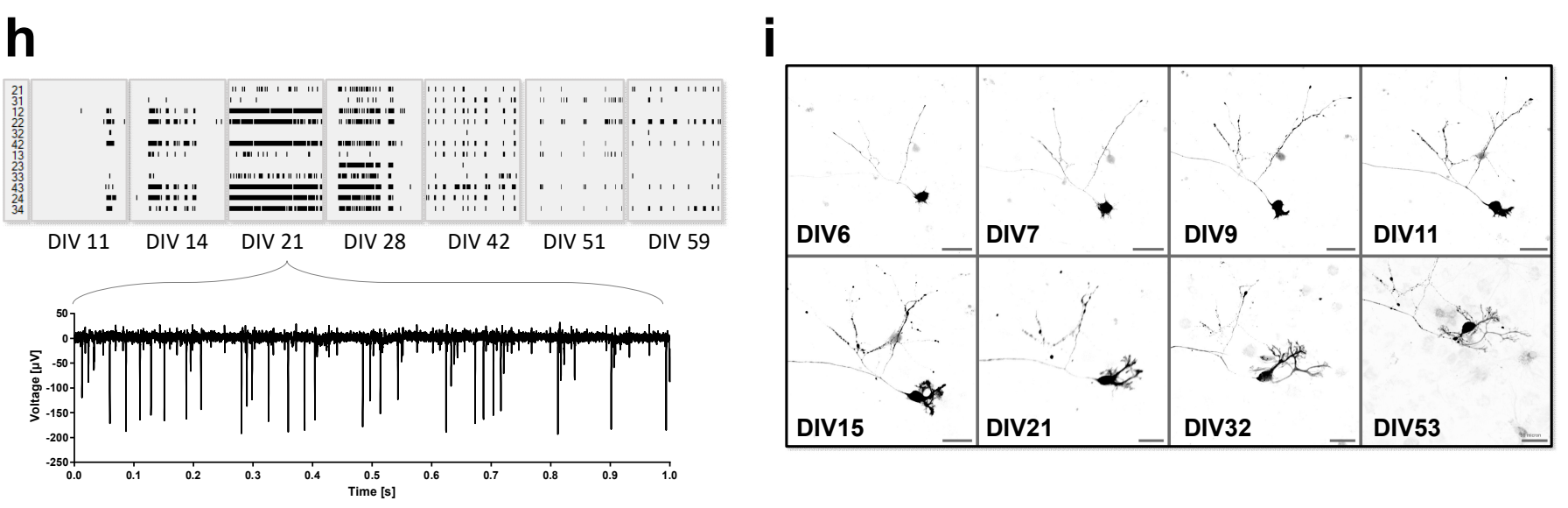
bioRxiv preprint doi: https://doi.org/10.1101/2020.05.20.105858; this version posted May 22, 2020. The copyright holder for this preprint (which

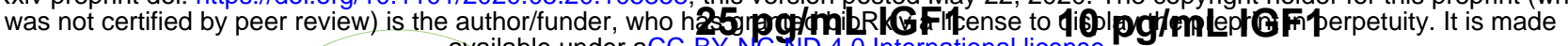

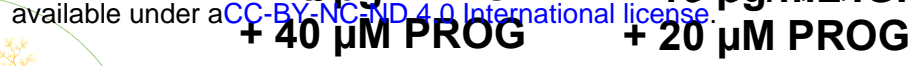

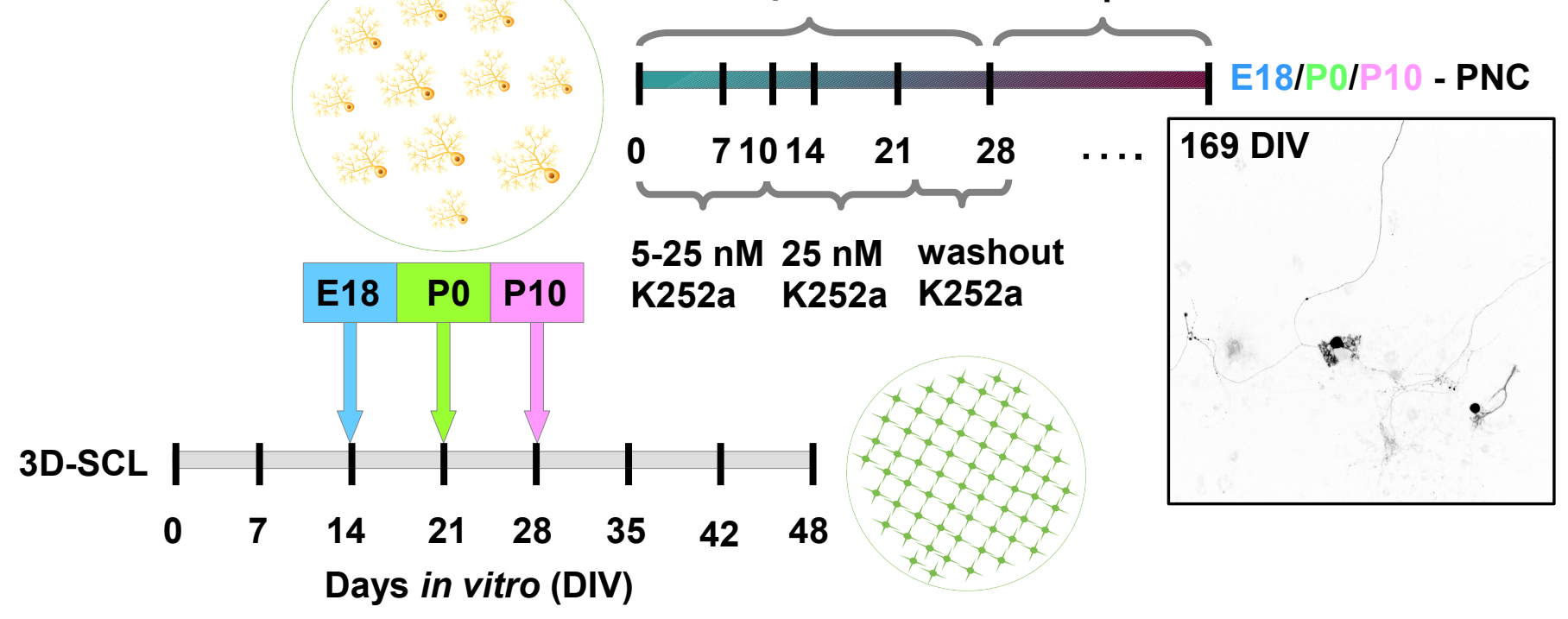

